\title{
Engaging Students With the Creative Art of Civil Engineering
}

\section{Dr. Aatish Bhatia, Princeton University}

Aatish Bhatia is an Associate Director (Engineering Education) in Princeton University's Council on Science and Technology. He works with faculty in engineering and related disciplines on incorporating active learning in the classroom and bringing science and engineering to a wider audience.

\section{Dr. Maria E. Garlock P.E., Princeton University}

Maria Garlock is an Associate Professor at Princeton University in the Department of Civil and Environmental Engineering where she is the Director of the Architecture and Engineering Program. Her scholarship is in resilient building design and in studies of the best examples of structural designs of the present and past. She has co-authored the book Felix Candela: Engineer, Builder, Structural Artist and has recently launched a MOOC titled "The Art of Structural Engineering: Bridges."

\section{Dr. Evelyn Hanna Laffey, Princeton University}

Dr. Evelyn Hanna Laffey is the Associate Director of the Princeton University Council on Science and Technology. Previously, she served as the Assistant Dean for Engineering Education at the Rutgers University School of Engineering. She has a bachelors degree in mathematics and doctorate in mathematics education from Rutgers University. She has over fifteen years of experience working with K-16 students and educators. She is interested in exploring the intersection of cognition, affect, and identity within STEM education and operationalizing research findings to provide an excellent and equitable education to all students. 


\section{Engaging Students With The Creative Art of Civil Engineering}

\section{Introduction and Overview}

We report on the progress of a multi-institutional NSF-funded education project called the Creative Art of Structural and Civil Engineering. The specific goals of the project are to:

1. Transform an introductory engineering course with dramatically improved interactivity and accessibility for students of all backgrounds and majors; 2. Ensure that the course takes a form that can be readily adopted into the engineering and general education curricula of many types of institutions of higher learning; 3. Facilitate the dissemination, adoption, and continuous improvement of these course materials and teaching methods.

In this paper, we focus on the version of this course taught at Princeton University, Structures and the Urban Environment, and report on our progress on the first goal above. This elective course has an enrollment of approximately 150 students, comprising of students from all majors and disciplines. The course examines the great works of engineers through case studies, critically evaluating them on scientific and aesthetic grounds, as well as analyzing the social context in which these works arose. For example, the minimal and sleek reinforced concrete bridges of Robert Maillart [1], or the ultra-lightweight thin-shell structures built by Félix Candela [2] highlight how engineers can innovate with new materials to develop new aesthetic forms. Furthermore, by integrating efficiency, economy, and elegance, these works stress the importance of finding optimal forms for structures, and demonstrate how great works of engineering can be well-integrated into their environment.

This project is relevant to the wider civil engineering community as it serves to engage a wide student body (majoring in STEM, the social sciences, and the humanities) in understanding and appreciating the role of civil engineers in society. Furthermore, by spreading inspiring and engaging introductory course materials that adopt research-based teaching methods, integrate STEM with the humanities, and emphasize the social relevance, technical challenges, and creative aspects of the discipline, this project helps meet an urgent need to improve the retention of students in STEM disciplines.

Since the launch of this project our activities have included: developing, implementing, and documenting active learning exercises and lecture materials; developing and analyzing student surveys; conducting interviews and focus groups; identifying themes and learning goals; developing a website to disseminate teaching materials; organizing annual workshops for universities interested in adopting course materials and teaching methods; and continuing to mentor workshop participants. 


\section{Interactive Teaching Methods Adopted in This Course}

As of May 2015, we have modified $80 \%$ of the course lectures to make use of active learning pedagogies, such as interactive lecture demonstrations, hands-on activities, polling questions, and discussion questions. We are continuing to work towards developing further interactive teaching exercises for this course.

\section{Promoting Student Interaction Through Polling and Discussion Questions}

Classroom response systems have been shown to be effective in raising the level of student engagement in college courses. In this course, we made use of Poll Everywhere, a classroom response system in which students submit answers to questions via text message or internet connected devices. We used this technology to help motivate a topic, to elicit discussion, to assess understanding, and to encourage experiential learning. Here we provide examples of each such use.

1. To motivate a topic: When introducing the lecture 'The Eiffel Tower and the Washington Monument', we use a series of quantitative reasoning and estimation questions to guide students into thinking about how a nearly 1,000 foot tall iron structure weighing 7,300 tons can be considered 'lightweight' (Figure 1). The answers to these questions are surprising and run counter to students' initial expectations, thereby naturally generating curiosity as to how Eiffel was able to arrive at such a lightweight form for his tower. This then helps motivate students to understand the scientific principles behind the shape of the Eiffel tower.

In the same lecture, we use an open-ended response question to ask students to provide one word to describe their impressions of the Eiffel Tower. We then use Poll Everywhere to display a word cloud of student responses, and these generally positive responses provide a stark contrast to the overwhelmingly negative critiques of the Tower's aesthetics when it was first constructed. This brief activity motivates the idea that societal views on the aesthetics of the Eiffel Tower have changed considerably since it was built. 


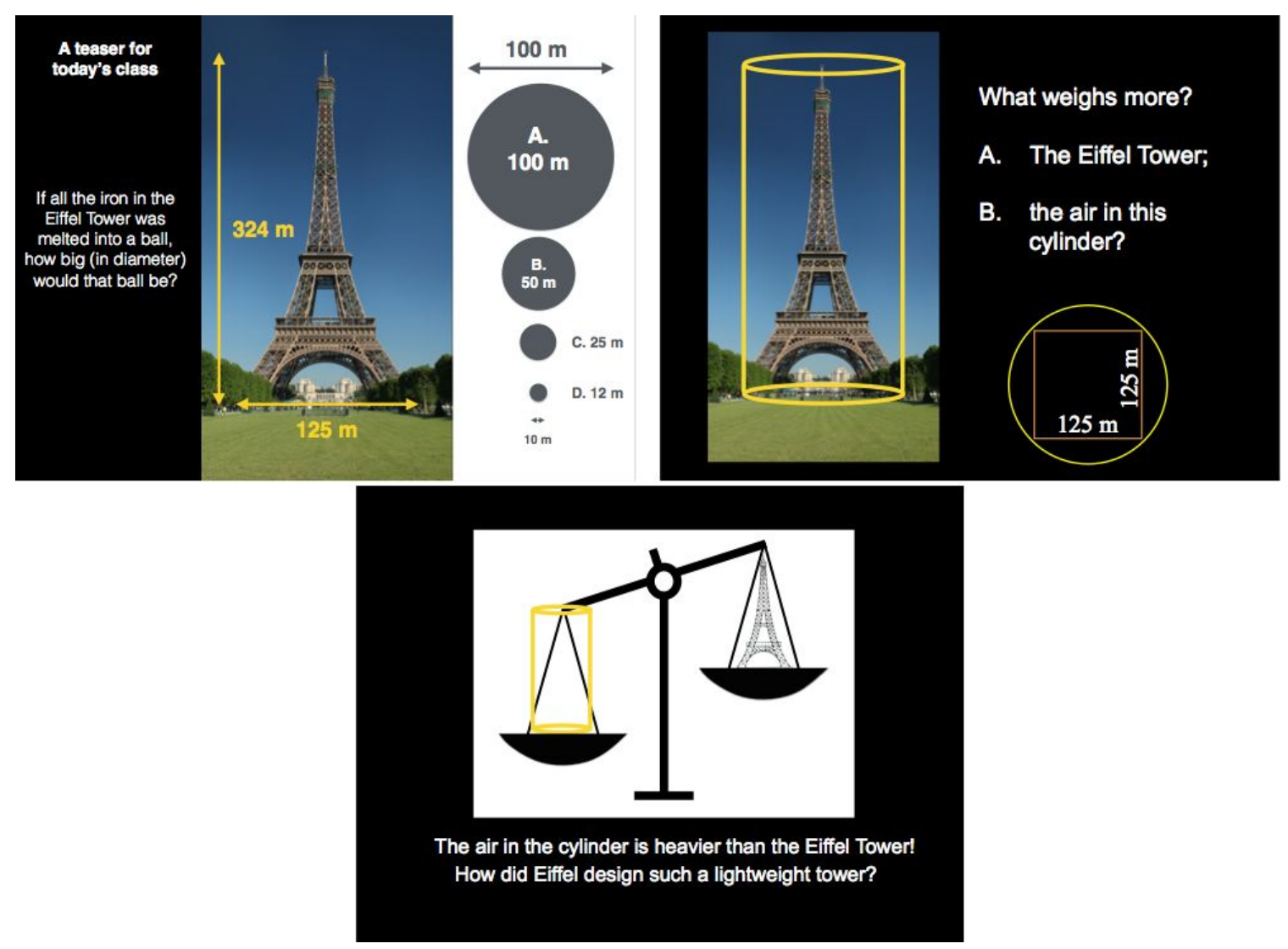

Figure 1: A series of questions used to motivate the lightness of the Eiffel Tower.

Image: Aatish Bhatia / Maria Garlock. Eiffel Tower Image: Benh Lieu Song (Creative Commons License)

2. To elicit discussion. In a lecture on the work of Christian Menn and the new bridge forms made possible by prestressed concrete, we used open-ended response questions to elicit student discussions. The students are asked to compare and contrast the merits of different proposals, and critique works on the criteria of structural art (Figure 2).

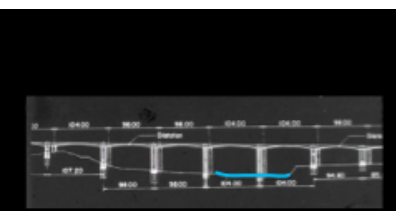

Piguet Design, Felsenau

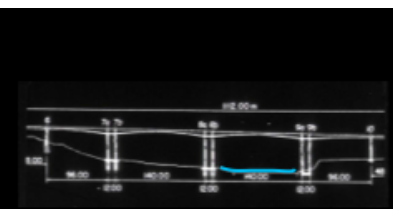

Menn Design, Felsenau

What advantages (scientific, social, or symbolic) does Menn's design proposal have over Piguet's design proposal for the Felsenau Bridge? Take a minute, come to a consensus with your neighbor, and then type/text response

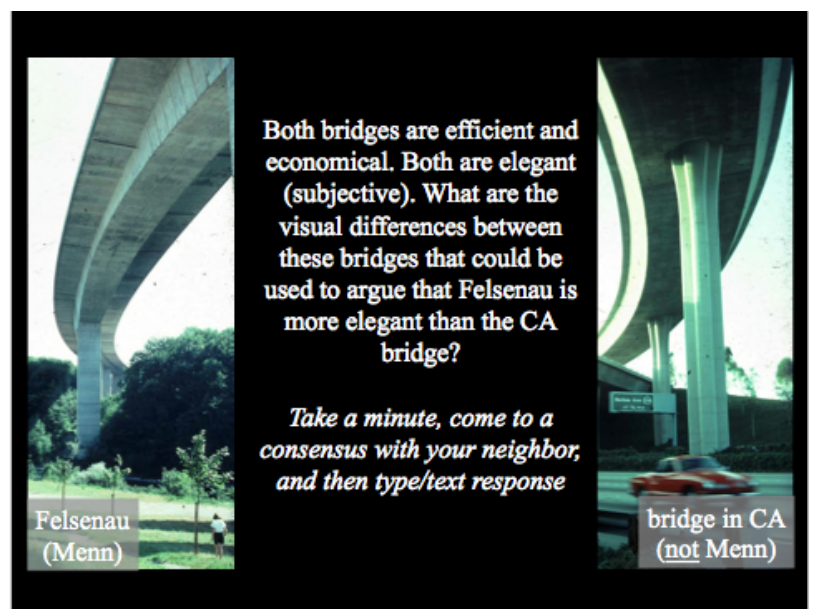

Both bridges are efficient and conomical. Both are elegan (subjective). What are the unal differences between hese bridges that could be sed to argue that Felsenau is bridge? onsensus with your neighbo and then type/text response

bridge in $\mathrm{CA}$

Figure 2: Examples of open-ended questions used to elicit discussions on structural art. Image: Maria Garlock 
3. To assess understanding. We frequently ask students conceptual questions to gather formative assessment. We adopt a 'think-pair-share approach' to encourage peer teaching, asking students to discuss questions with their neighbors and re-vote when there is no clear consensus on the correct answer. For example, in a lecture on the Golden Gate Bridge we ask students to consider how the height of the towers would affect the cable size (Figure 3).

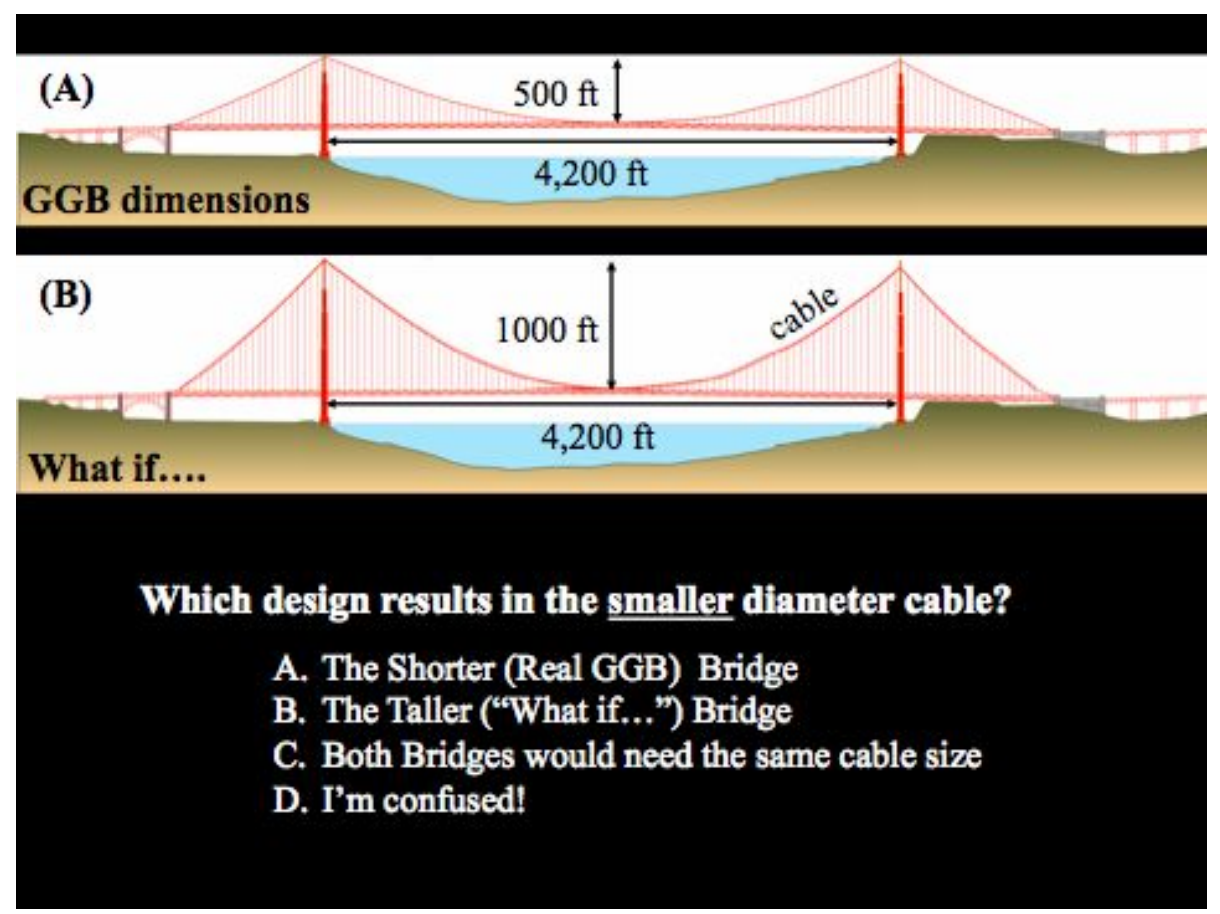

Figure 3: A polling question to assess understanding of the relation between form and forces in a suspension bridge. Image: Maria Garlock

4. To encourage experiential learning. Here we use a sequence of polling questions to guide students through an interactive lecture demonstration or hands-on activity.

\section{Encouraging experiential learning through lecture demonstrations and hands-on activities}

We typically implement an interactive lecture demonstration in three stages: predict, experience, and reflect [3]. In the first step, students make their predictions about the outcome of an experiment or demonstration. For example, we cover the works of Eduardo Torroja and Félix Candela, both engineers and builders who exploited the inherent stiffness of curved surfaces to create remarkably lightweight thin-shell concrete structures [2]. We introduce this topic by asking students to use a sheet of paper, a paper clip, and a cup to construct a paper cantilever that can hold as many Hershey's Kisses chocolates as possible at its unsupported end [4]. Before beginning the activity, students first predict how many Hershey's Kisses they expect their paper structure to hold (Figure 4). 


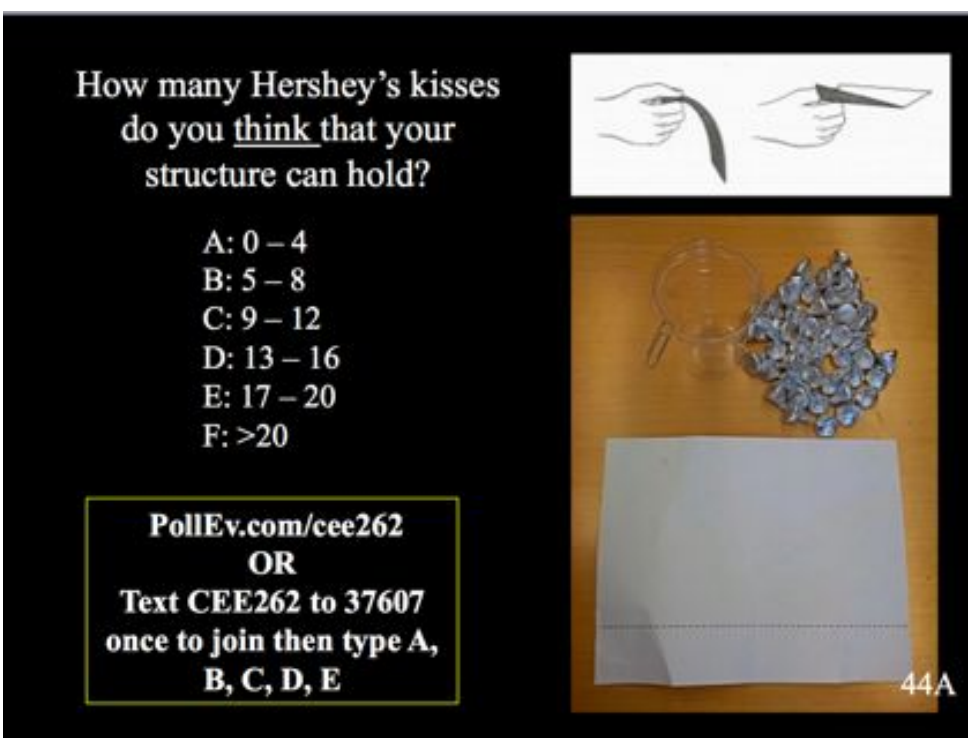

Figure 4: Prediction stage in a hands-on activity to build a paper cantilever. Image: Maria Garlock

In the second step, students experience or observe the activity. In this case, they work in pairs and compete to see whose structure supports the greatest number of Hershey's Kisses. The instructor highlights the different design choices made by the groups. Through these explorations, students can discover that forms incorporating curvature have greater stiffness.

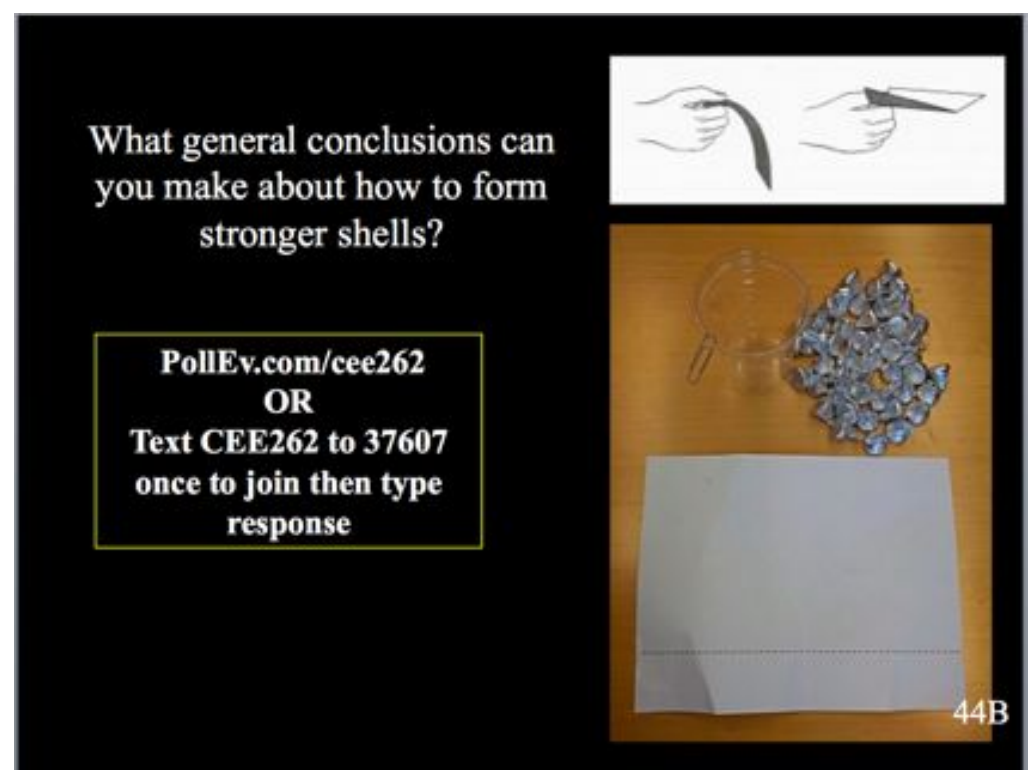

Figure 5: Reflection stage in a hands-on activity to build a paper cantilever. Image: Maria Garlock

In the last step, students reflect on the outcome of the activity (Figure 5). Activities that elicit surprise or where the outcome deviates from students' expectations work particularly well as lecture demonstrations. Pairing a prediction with an experience or observation highlights 
inconsistencies that may exist between the student's prior experiences and the novel concepts they are encountering. Finally, the reflection step provides an opportunity for students to synthesize and apply this new understanding.

In the reflection stage of the paper cantilever activity, the student responses emphasized the importance of form in influencing the overall strength of a structure, and that curving a surface in one direction can create stiffness in other direction. We further connect this to students' everyday experiences by mentioning this is the same engineering principle behind the 'fold hold', where bending a slice of pizza prevents it from drooping (Figure 6). This hands-on activity is then used as an entry point to appreciate and understand the thin-shell works of Torroja and Candela.
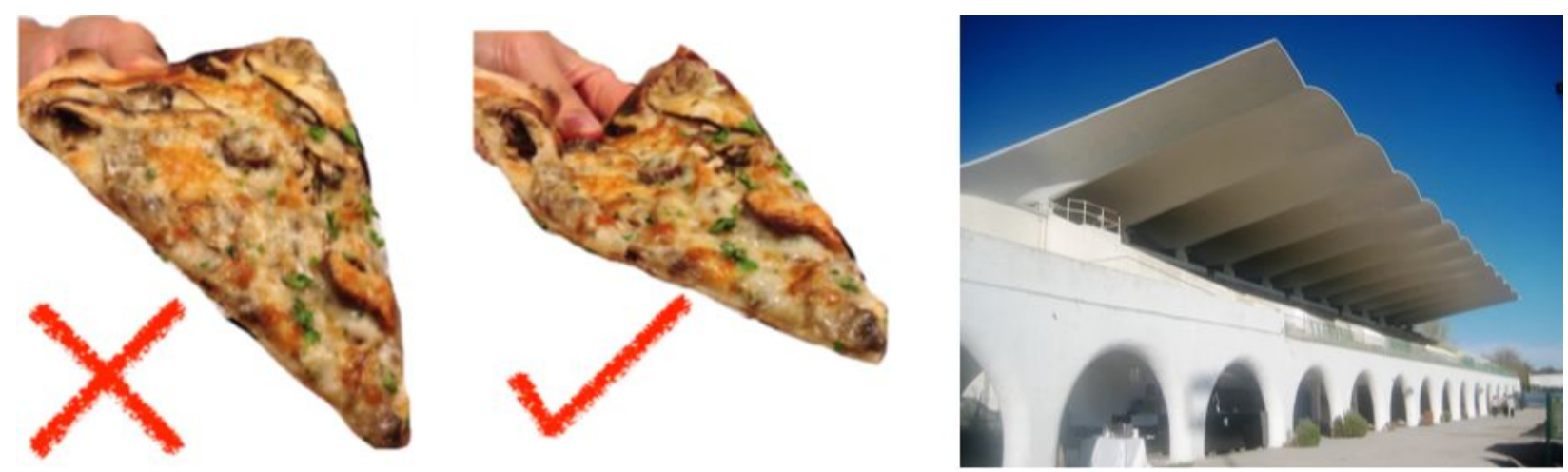

Figure 6: (Left) Illustration of 'fold hold' on a pizza slice. Image: Aatish Bhatia. (Right) Roof of the La Zarzuela Racetrack (Madrid, Spain) designed by Eduardo Torroja. Image: Outisnn / Wikimedia

\section{Highlighting Societal Context Through Case Studies}

A central focus of this course is to teach engineering through case studies. Teaching engineering through case studies rather than abstract examples helps students see the societal impact of engineering and relate works of engineering to the social, political and cultural contexts in which they arose [5].

For example, in a new lecture developed on the topic of Ethics in Engineering, we cover the story of the 1978 Citicorp Center Crisis. We incorporate video clips from a BBC documentary on this incident, as well as audio from 99 Percent Invisible podcast [6] interviewing Professor David Billington and his former student, Diane Hartley, whose undergraduate thesis work identified the critical flaw in the building's design. In lecture, we pose students the question of whether the public should have been informed of the impending danger, and discuss the lapses of engineering ethics. These discussions are further continued in lecture recitations. 
In the same lecture, we also discuss the ethics involved in the balance between elegance and economy in the public works projects of Santiago Calatrava, and compare and contrast the Alamillo Bridge designed by Santiago Calatrava and the neighboring Barqueta Bridge built by Juan José Arenas and Marcos Pantaleón in the city of Seville, Spain.

\section{Learning Outcomes}

We adapted the Student Assessment of their Learning Gains survey [7,8] to assess learning outcomes. In the first year of implementing this project, a large majority of students reported moderate, good, or great learning gains from lecture demonstrations (94\%), the instructional approach taken in the class $(90 \%)$, and hands-on activities (83\%) (Figure 7). With regard to course themes, $80 \%$ or more of students reported moderate to great learning gains in evaluating significant works of civil engineering based on their social, scientific and symbolic importance; relating the forms of structures they encounter in daily life to their function and to forces; possessing an aesthetic and technical appreciation for bridges, towers, shells, and other structures; and comparing, contrasting, and critiquing structures as works of structural art. These results highlight the efficacy of the teaching methods adopted and active learning exercises developed and implemented in this project. Further details about our evaluation methods and results can be found in the ASEE 2016 paper entitled 'Enhancing Student Cognition and Affect through the Creative Art of Structural and Civil Engineering' [9].

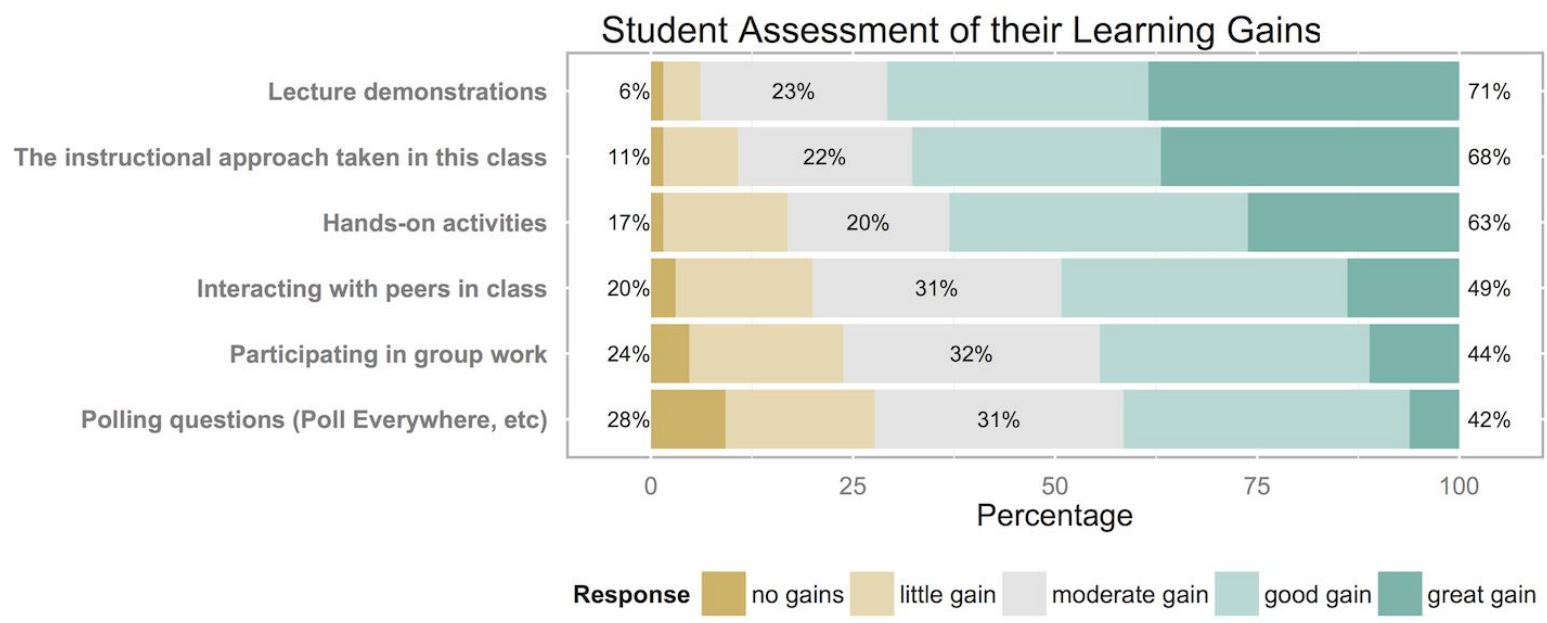

Figure 7: Survey results pertaining to interactive teaching methods 


\section{Acknowledgements}

This material is based upon work supported by the National Science Foundation under Grant no.: 1432426. Any opinions, findings, and conclusions or recommendations expressed in this material are those of the author(s) and do not necessarily reflect the views of the National Science Foundation.

\section{References}

1. Billington, David P. The Tower and the Bridge: The New Art of Structural Engineering. Princeton University Press, 1985.

2. Garlock, Maria E. Moreyra, and David P. Billington. Félix Candela: Engineer, Builder, Structural Artist. Yale University Press, 2008.

3. Interactive Lecture Demonstrations. Dorothy Merritts, Robert Walter, Bob MacKay, Mark Maier, Rochelle Ruffer, Sue Stockly and Ronald Thornton. Accessed May 1, 2016. http://serc.carleton.edu/introgeo/demonstrations/index.html

4. Garlock, Maria E. Moreyra, Aatish Bhatia, and Negar Elhami-Khorasani. "Introducing Modern Teaching into a Classic Course on Structural Art.” IABSE Symposium Report, 105:1-2. International Association for Bridge and Structural Engineering, 2015.

5. Committee on the Engineer of 2020, and others. Educating the Engineer of 2020:: Adapting Engineering Education to the New Century. National Academies Press, 2005.

6. Structural Integrity - 99\% Invisible. (2014). Accessed May 1, 2016. http://99percentinvisible.org/episode/structural-integrity/

7. Seymour, Elaine, D. Wiese, A. Hunter, and Susan M. Daffinrud. "Creating a Better Mousetrap: On-Line Student Assessment of Their Learning Gains." National Meeting of the American Chemical Society, 2000.

8. "SALG - Student Assessment of Their Learning Gains.” Accessed May 2, 2016. http://www.salgsite.org/

9. Laffey, Evelyn H., Maria E. M. Garlock, and Aatish Bhatia. "Enhancing Student Cognition and Affect through the Creative Art of Structural and Civil Engineering" ASEE Annual Conference and Exposition, 2016. 